\title{
Article \\ The CRISPR/Cas9 Minipig-A Transgenic Minipig to Produce Specific Mutations in Designated Tissues
}

\author{
Martin Fogtmann Berthelsen ${ }^{1}$, Maria Riedel ${ }^{1}$, Huiqiang Cai ${ }^{1}$, Søren H. Skaarup ${ }^{1,2}$, Aage K. O. Alstrup ${ }^{1,3}$, \\ Frederik Dagnæs-Hansen ${ }^{4}$, Yonglun Luo ${ }^{4,5}$, Uffe B. Jensen ${ }^{1}$, Henrik Hager ${ }^{6}$, Ying Liu ${ }^{7}$, Henrik Callesen ${ }^{7}$, \\ Mikkel H. Vendelbo ${ }^{3,4}$, Jannik E. Jakobsen ${ }^{4}$ and Martin Kristian Thomsen ${ }^{4,8, *}$
}

check for updates

Citation: Berthelsen, M.F.; Riedel, M.; Cai, H.; Skaarup, S.H.; Alstrup, A.K.O.; Dagnæs-Hansen, F.; Luo, Y.; Jensen, U.B.; Hager, H.; Liu, Y.; et al. The CRISPR/Cas9 Minipig-A Transgenic Minipig to Produce Specific Mutations in Designated Tissues. Cancers 2021, 13, 3024. https://doi.org/10.3390/ cancers 13123024

Academic Editor: Kris L. Vleminckx

Received: 14 May 2021

Accepted: 14 June 2021

Published: 16 June 2021

Publisher's Note: MDPI stays neutral with regard to jurisdictional claims in published maps and institutional affiliations.

Copyright: (c) 2021 by the authors. Licensee MDPI, Basel, Switzerland. This article is an open access article distributed under the terms and conditions of the Creative Commons Attribution (CC BY) license (https:// creativecommons.org/licenses/by/ $4.0 /)$.
1 Department of Clinical Medicine, Aarhus University, 8200 Aarhus, Denmark; mfb@biomed.au.dk (M.F.B.); maria.riedel@biomed.au.dk (M.R.); huiqiang.cai@clin.au.dk (H.C.); soerskaa@rm.dk (S.H.S.); aagealst@rm.dk (A.K.O.A.); uffejens@rm.dk (U.B.J.)

2 Department of Respiratory Diseases and Allergy, Aarhus University Hospital, 8200 Aarhus, Denmark

3 Department of Nuclear Medicine \& PET, Aarhus University Hospital, 8200 Aarhus, Denmark; mhve@biomed.au.dk

4 Department of Biomedicine, Aarhus University, 8000 Aarhus, Denmark; fdh@au.dk (F.D.-H.); ALUN@biomed.au.dk (Y.L.); JEJ@biomed.au.dk (J.E.J.)

5 Lars Bolund Institute of Regenerative Medicine, BGI-Qingdao, BGI-Shenzhen, Shenzhen 518083, China

6 South Denmark Hospital, 7100 Vejle, Denmark; henrik.hager@rsyd.dk

7 Department of Animal Science, Aarhus University, 8830 Tjele, Denmark; ying.liu@anis.au.dk (Y.L.); henrik.callesen@anis.au.dk (H.C.)

8 Aarhus Institute of Advanced Studies (AIAS), Aarhus University, 8000 Aarhus, Denmark

* Correspondence: mkt@biomed.au.dk

Simple Summary: Research in large animal models has been hampered by the complexity to introduce new gene alterations, but this has been simplified by the discovery of the CRISPR/Cas system. Here, we have cloned a Cas9 minipig to generate a porcine model for pre-clinical research. Six viable piglets were produced and backcrossed to Göttingen minipigs for two generations. Primary cells from different organs were isolated, and multiple gene alterations were performed by CRISPR in vitro. In vivo activation of the Cas9 expression was conducted by viral delivery of the FlpO expression to the skin. Overall, we successfully cloned a Cas9-expressing minipig and confirmed gene alterations introduced by the CRISPR/Cas system to porcine cells.

Abstract: The generation of large transgenic animals is impeded by complex cloning, long maturation and gastrulation times. An introduction of multiple gene alterations increases the complexity. We have cloned a transgenic Cas9 minipig to introduce multiple mutations by CRISPR in somatic cells. Transgenic Cas9 pigs were generated by somatic cell nuclear transfer and were backcrossed to Göttingen Minipigs for two generations. Cas9 expression was controlled by FlpO-mediated recombination and was visualized by translation from red to yellow fluorescent protein. In vitro analyses in primary fibroblasts, keratinocytes and lung epithelial cells confirmed the genetic alterations executed by the viral delivery of single guide RNAs (sgRNA) to the target cells. Moreover, multiple gene alterations could be introduced simultaneously in a cell by viral delivery of sgRNAs. Cells with loss of TP53, PTEN and gain-of-function mutation in KRAS ${ }^{\mathrm{G} 12 \mathrm{D}}$ showed increased proliferation, confirming a transformation of the primary cells. An in vivo activation of Cas9 expression could be induced by viral delivery to the skin. Overall, we have generated a minipig with conditional expression of Cas9, where multiple gene alterations can be introduced to somatic cells by viral delivery of sgRNA. The development of a transgenic Cas9 minipig facilitates the creation of complex pre-clinical models for cancer research.

Keywords: CRISPR; cancer; animal models; porcine model; lung cancer; handmade cloning; TP53; STK11; KRAS; Göttingen minipigs 


\section{Introduction}

Breakthroughs in regards to diagnosis and treatment of diseases, including cancer, have often been obtained from studies in small animal models. Here, the mouse is the preferred model, highlighted by the number of models generated [1]. However, discoveries determined in murine disease models are often untranslatable to the clinic [2]. It has been demonstrated that animals with larger body mass and a higher number of cells have developed distinct mechanisms to avoid cancer, which are not found in the mouse [3]. A large disease model, such as the pig, could, thus, help to increase the success rate for bridging basic biomedical studies to clinical trials. Compared to mice, pigs are more similar to humans in the majority of biological aspects [4-6]. Porcine cancer models have been generated with limited success, compared to the large number of mouse models [7-14]. Single gene alteration has often not resulted in cancer, and transgenic pigs with overexpression of oncogenes have resulted in other complications that have compromised the model $[13,14]$. The few successful cancer models in pigs have revealed new aspects of cancer biology, for example highlighted by the insight to TP53, which is not evolutionary conserved to the mouse [15]. Hence, large animals can contribute to understanding cancer biology, leading to better cancer treatments.

The CRISPR/Cas9 system consists of the Cas9 endonuclease and single guide RNA (sgRNA) that must be present simultaneously to induce genetic modifications [16]. The CRISPR/Cas9 system induces mutations at the sgRNA target site by deletions or insertions (Indel) of base pairs, which often disrupt the reading frame [16]. The CRISPR/Cas9 system has been applied to in vivo studies and is widely used in mouse studies [16-18]. The method has multiple advantages, especially by simultaneous multiplex gene alteration in somatic cells. For example, lung cancer has been induced in mice by targeting Trp53, Stk11 and Kras, followed by rapid cancer development [19,20].

Transgenic porcine disease models are generated by expensive and time-consuming methods such as pronuclear injection or somatic cell nuclear transfer (SCNT). Notably, cloning is inefficient and only a few percent of the implanted blastocysts/morulae will result in viable piglets [21-23]. In addition, an intercrossing of different porcine models is laborious due to the long generation time compared to rodents. Applying the CRISPR/Cas9 system to large animal models, such as pigs, could overcome some of the obstacles with generating new lines and study multiple gene alterations in vivo and in vitro.

Here, we cloned a minipig with inducible Cas9 expression that can be activated upon delivery of FlpO recombinase. Transgene expression was visualized by red fluorescent protein (RFP) expression. Activated, Cas9-expressing cells were visualized by a shift to expression of yellow fluorescent protein (YFP). Cas9-expressing minipigs were cloned by SCNT and backcrossed to Göttingen Minipigs for two generations. Two different clones were obtained with strong transgene expression levels across different organs. The isolation of fibroblast, keratinocytes and lung epithelial cells showed strong transgene expression and activation in vitro. Furthermore, successful gene alterations were performed by the delivery of sgRNA's. Multiple gene alterations transformed the porcine cells in vitro and increased cell proliferation. In vivo activation of Cas9 expression was performed in the skin, validating the design of the construct in vitro and in vivo.

\section{Materials and Methods}

\subsection{Animals}

All experiments were carried out at Aarhus University and Aarhus University Hospital. The cloned pigs were mixed-race minipigs. F1 and F2 offspring were obtained by backcrossing with Göttingen Minipigs from Ellegaard Göttingen Minipigs, Dalmose, Denmark [24]. WT control pigs were age-matched Danish Landrace-Yorkshire pigs. Deeply sedated pigs were euthanized by intra-cardiac injection of $30 \%$ pentobarbital $(1 \mathrm{~mL}$ pr. $10 \mathrm{~kg}$ body mass). 


\subsection{Vector Construction}

The CRISPR-Cas9 transposon vector (LIR_TRE_CAG_mKateII-Puro-STOP_mVenusCas9-PA-RIR, Addgene no. 68345) was constructed over multiple cloning steps. In brief, an A2-linked Venus gene was added to the pX330-U6-Chimeric_BB-CBh-hSpCas9 plasmid (Addgene no. 42230), using the AgeI and BgIII restriction sites. Next, the Venus-2A-Cas9 construct was transferred to the TRE VKCS_KRAB with the stopper kat_Puro plus ROX SV40PA_GOLD Global plasmid (Addgene no. 67277), using the NotI and AgeI restriction sites. Finally, Katushka was replaced with synthesized mKate2, using the PacI and AvrII restriction sites.

The PKT plasmid was generated by inserting a synthesized pig KRASG12D repair template and $3^{\prime}$ AAV2 ITR into the AAV_3xgRNA;PTENA, p53B,SMAD4A_CAG _FIPO_synthPA plasmid (Addgene no. 68346), using the RsrII and KasI restriction sites. Next, the SMAD4 sgRNA was replaced by a KRAS sgRNA that was inserted into the pSpCas9(BB)-2A-GFP (PX458) plasmid (Addgene no. 48138), using the ClaI and KpnI restriction sites.

The PTKN plasmid was generated by inserting the NOTHC1 sgRNA, which was inserted into the pSpCas9(BB)-2A-GFP (PX458) plasmid that was cloned into the PKT plasmid using the KpnI site.

The SKT plasmid was generated by replacing the PTEN and TP53 sgRNAs with a STK11 sgRNA that was inserted into the pSpCas9(BB)-2A-GFP (PX458) plasmid (Addgene no. 48138) using the NotI and ClaI restriction sites. Subsequently, the TP53 sgRNA was re-inserted using the KpnI restriction site.

\subsection{Single Guide RNA (sgRNA) Design and Validation}

The sgRNAs were designed using a CRISPR design tool. See Table S1 for sgRNA sequences and genomic primers. The guide efficacy was determined with the TIDE (Tracking of Indels by Decomposition) software through transfection of porcine fibroblasts with the pSpCas9(BB)-2A-GFP plasmid (Addgene ID: 48138), harbouring the designated sgRNA followed by FACS of GFP positive cells.

\subsection{ICE Analysis}

Sanger sequencing of PCR products from the target site of the guides was analysed by the ICE v2 CRISPR Analysis Tool to identify mutations.

\subsection{Handmade Cloning (HMC), Culture and Transfer of Embryos}

Porcine fibroblasts were cultured from ear biopsies of juvenile mixed-race minipigs as previously described [25]. Transfection with $400 \mathrm{ng}$ LIR_TRE_CAG_mKateII-PuroSTOP_mVenus-Cas9-PA-RIR transposon plasmid and $50 \mathrm{ng}$ hyperactive Sleeping Beauty transposase plasmid using the Turbofect Transfection Reagent according to the manufacture's recommendations (Thermo Scientific, Roskilde, Denmark) generated the transgenic Cas9 fibroblasts. Positive cells were selected with puromycin (Sigma-Aldrich, Søborg, Denmark) for 8 days. The resistant colonies were analysed by assessment of the RFP fluorescent signal using a fluorescence microscope to determine their fluorescent profile. A pool of cells with different fluorescent intensity profiles were selected and grown for 9 days prior to SCNT by HMC, as described [26]. The reconstructed, transgenic embryos were cultured in vitro for 5 to 6 days, and selected blastocysts/morulae were surgically transferred to a Danish Landrace recipient sow. Cloned, transgenic piglets were delivered by natural farrowing on day 115 and raised by their surrogate mother. From the 85 blastulas/morulas transferred to the surrogate mother, 10 male minipigs were produced, of which 3 were stillborn.

\subsection{Cell Work}

Primary porcine fibroblasts were isolated from ear biopsies of neonatal transgenic piglets. Single cells were obtained by trypsin treatment and then expanded in DMEM con- 
taining $100 \mathrm{U} / \mathrm{mL}$ penicillin, $0.1 \mathrm{mg} / \mathrm{mL}$ streptomycin (Sigma-Aldrich, Søborg, Denmark), and $15 \%$ foetal bovine serum (Gibco, Roskilde, Denmark) at $37.5^{\circ} \mathrm{C}$.

Primary Cas 9 keratinocytes were isolated from ear biopsies from neonatal Cas9 minipigs by bisecting the biopsies, whereby the epidermis was exposed. The explants were placed in culture flasks and incubated bottom-up overnight at $37.5^{\circ} \mathrm{C}$. Outgrowth and expansion of keratinocytes was achieved in DMEM supplemented with $15 \%$ foetal bovine serum (Gibco, Roskilde, Denmark), $100 \mathrm{U} / \mathrm{mL}$ penicillin, $0.1 \mathrm{mg} / \mathrm{mL}$ streptomycin, $265 \mathrm{mg} / \mathrm{L}$ L-glutamine, $10 \mathrm{ng} / \mathrm{mL}$ EGF (Invitrogen, Roskilde, Denmark), $50 \mu \mathrm{M}$ gentamycin and $0.4 \mu \mathrm{g} / \mathrm{mL}$ hydrocortisone (Sigma-Aldrich, Søborg, Denmark) at $37.5^{\circ} \mathrm{C}$ for 7 to 10 days. Subsequently, the growth medium was changed to a serum-free keratinocyte medium, K-SFM, with an epidermal growth factor and bovine pituitary extract (Gibco, Roskilde, Denmark).

Fibroblasts and keratinocytes isolated from transgenic Cas9 piglets were transfected with a plasmid expressing Flp Optimized (FlpO) [27] under a ubiquitous CAG promoter to activate Cas9 and Venus expression or AAV particles carrying designated sgRNAs and FlpO. For the cell proliferation assay, 25,000 cells were seeded and counted after 3 days. Three different clones were used.

\subsection{Air-Liquid Interface (ALI) Culture of Porcine Tracheobronchial Epithelial Cells}

Porcine Cas9 lung tissue resections were transported and incubated for $72 \mathrm{~h}$ in DMEM (Sigma-Aldrich, Søborg, Denmark) with $1 \times$ Antibiotic-Antimycotic (Gibco, Roskilde, Denmark) and $1 \times$ Gentamicin solution, $0.1 \mathrm{mg} / \mathrm{mL}$ protease and $0.01 \mathrm{mg}$ DNase (SigmaAldrich, Søborg, Denmark). Porcine tracheobronchial epithelial cells were harvested by scraping off the cells with a scalpel, FCS was added to inactivate the protease, and the media containing the brownish film with basal epithelial cells were centrifuged for $5 \mathrm{~min}$ at $500 \times g$. The pellets were washed in Hanks' Balanced Salt solution, BBS (Sigma-Aldrich, Søborg, Denmark), centrifuged for $5 \mathrm{~min}$ at $500 \times g$ and resuspended in BEGM (Lonza, Copenhagen, Denmark) with $1 \times$ Antibiotic-Antimycotic. The resuspended cells were plated in petri dishes for $2 \mathrm{~h}$, where the remaining fibroblasts bound to the surface and the epithelial cells stayed in suspension. Subsequently, the suspended cells were transferred to type I and III collagen-coated dishes for expansion. Expanded basal cells were detached by trypsin treatment, centrifuged for $5 \mathrm{~min}$ at $500 \times \mathrm{g}$ in PneumaCult ${ }^{\mathrm{TM}}$-ALI Medium (STEMCELL Technologies, Grenoble, France) at a density of 105 cells $/ \mathrm{mL}$, followed by seeding the cells onto type IV collagen (Sigma-Aldrich, Søborg, Denmark)-coated Transwell permeable supports ( $24 \mathrm{~mm}, 0.4 \mu \mathrm{m}$ polyester membrane, Corning, Wiesbaden, Germany). $1 \mathrm{~mL}$ of ALI medium was added to the lower reservoir, and $0.5 \mathrm{~mL}$ of cell suspension was added to the upper reservoir. In less than 7 days, at $37^{\circ} \mathrm{C}$ in $5 \% \mathrm{CO}_{2}$, when cells were confluent, an ALI was formed by removing the apical medium, and the cells were fed with medium only from the basal compartment. Cultures were maintained under ALI conditions for at least 21 days prior to treatment to ensure formation of a pseudo lung epithelium.

\subsection{In Vivo Imaging Systems Analysis}

Organ biopsies from Cas9 minipigs, transported in ice-cold PBS, were used for ex vivo IVIS analysis to detect a fluorescent protein signal, using an IVIS Spectrum Preclinical In Vivo Imaging System (Perkin Elmer, Copenhagen, Denmark). The RFP signal was detected by excitation at $570 \mathrm{~nm}$ and emission at $640 \mathrm{~nm}$. Data were collected in the form of average fluorescence radiant efficiency ((photons $/ \mathrm{s} / \mathrm{cm}^{2} /$ steradian $\left.) /\left(\mu \mathrm{W} / \mathrm{cm}^{2}\right)\right)$ and analysed with the Living Image software (Caliper Life Science, Copenhagen, Denmark). Organ biopsies from an age-matched Danish landrace pig were used as negative controls.

\subsection{Fluorescence-Assisted Cell Sorting}

Cell sorting was carried out using a BD FACSAria III high-speed cell sorter. GFP or YFP positive cells were analysed at a velocity of 2000 cells/s and sorted into a culture plate with DMEM ranging from 1 to 2000 cells per well at $4{ }^{\circ} \mathrm{C}$. 


\subsection{Southern Blot Analysis}

Genomic DNA was isolated from the chorion villi lysis buffer treated Cas9 pig fibroblasts. Southern blotting was performed on $15 \mu \mathrm{g}$ DNA from each piglet, digested with $5 \mu \mathrm{L}$ XmaJI for $12 \mathrm{~h}$ (Thermo Scientific, Roskilde, Denmark) and spiked with $3 \mu \mathrm{L}$ XmaJI for another $4 \mathrm{~h}$ of incubation, as described [28]. The RFP DNA probe ( $656 \mathrm{bp}$ ) was purified from restriction-cleaved plasmid DNA and labelled with 32P-dCTP EasyTide (Perkin Elmer, Copenhagen, Denmark) using the Prime-It Random Labeling Kit (Agilent Technologies, Glostrup, Denmark). The X-ray film was developed at $-70^{\circ} \mathrm{C}$ for $48 \mathrm{~h}$.

\subsection{AAV Production}

An amount of $90 \%$ confluent HEK293T cells, seeded on $15 \mathrm{~cm}$ dishes in $22 \mathrm{~mL}$ DMEN with $10 \%$ FCS and $1 \times$ pen-strep, were transfected with $14 \mu$ g Adeno-Helper plasmid; $14 \mu \mathrm{g}$ serotype 6, 9, or 2H22 capsid plasmid; $14 \mu \mathrm{g}$ viral construct plasmid, and $2.2 \mu \mathrm{g}$ GFP plasmid (serving as transfection control), using the branched MW 25,000 polyethylenimine (PEI) (Sigma-Aldrich, Søborg, Denmark, 408727) transfection reagent. The PEI mixture consisted of $350 \mu \mathrm{L}$ PEI and $440 \mu \mathrm{L} \mathrm{H}_{2} \mathrm{O}$. The DNA mixture consisted of $44 \mu \mathrm{g}$ plasmid and $760 \mu \mathrm{L} \mathrm{H} \mathrm{H}_{2} \mathrm{O}$. A total of $790 \mu \mathrm{L} 0.3 \mathrm{M} \mathrm{NaCl}$ was added to both mixtures just before they were mixed. The transfection mixture was incubated for $10 \mathrm{~min}$, followed by an addition of $3.1 \mathrm{~mL}$ transfection mixture to each dish. Cells were harvested 48-72 post transfection using a cell scraper, collected in $50 \mathrm{~mL}$ tubes, and pelleted by centrifugation for $10 \mathrm{~min}$ at $400 \times g$. The pellets were resuspended in a total volume of $15 \mathrm{~mL}$ in PBS and lysed by 5 freeze-thaw cycles $\left(-196{ }^{\circ} \mathrm{C}\right.$ liquid nitrogen to $37^{\circ} \mathrm{C}$ water bath). Lysed cells were centrifuged at $4000 \times g$ for $5 \mathrm{~min}$, and the supernatant was transferred to a new $50 \mathrm{~mL}$ tube. Excess RNA and DNA was removed by benzonase (Sigma-Aldrich, Søborg, Denmark) treatment for $1 \mathrm{~h}$ at $37^{\circ} \mathrm{C}$ to a final concentration of $50 \mathrm{u} / \mathrm{mL}$. Next, the crude AAV prep was filtered through a $0.45 \mu \mathrm{m}$ filter using a syringe and then a $0.20 \mu \mathrm{m}$ filter. Finally, the AAV sample was concentrated by loading the sample on a $100 \mathrm{~K}$ protein concentrator (Thermo Scientific, Roskilde, Denmark), followed by centrifugation at $4000 \times g$ until the desired volume was reached. The AAV samples were titrated by qPCR analysis using a plasmid standard curve and 1000 to 100,000 fold dilutions of the AAV samples. The Brilliant III Ultra-Fast SYBR ${ }^{\circledR}$ Green QPCR Master Mix reagent (Aqilent Techonologies, Santa Clara, CA, USA) was used according to the manufacture's recommendations. See Table S1 for primers.

\subsection{AAV Delivery to Pig Lungs}

Delivery of AAV particles to the lungs of sedated pigs was facilitated by endobronchial spraying in a specified lung segment during a bronchoscopy or aerosolization of AAV particles with an Aerogen Pro nebulizer that was connected to a Dräger Primus anaesthesia machine. Hereby, $10^{12} \mathrm{vg} /$ pig SKT_AAV2H22 particles were administered to 3 pigs, $10^{12} \mathrm{vg} /$ pig of SKT_AAV2H22 and $5 \times 10^{11} \mathrm{vg} /$ pig of PKT_AAV9 to 3 pigs, and $10^{12} \mathrm{vg} / \mathrm{pig}$ of SKT_AAV2H22 and $10^{12} \mathrm{vg} /$ pig of PKT_AAV9 to 7 pigs.

\subsection{Construct Delivery to the Skin of the Pigs}

The PTKN construct was delivered to the skin of the Cas9 minipigs by either injecting $10^{12}$ PTKN_AAV6 particles, $10^{12}$ PTKN_AAV6 particles followed by electroporation, or electroporation of $100 \mu \mathrm{L}(1 \mu \mathrm{g} / \mu \mathrm{L})$ PTKN plasmid using a Cliniporator (IGEA, Wetherby, UK). The electric pulses consisted of 1 high-voltage pulse at $400 \mathrm{~V} / \mathrm{cm}$, duration $100 \mu \mathrm{s}$, and 1 low-voltage pulse at $56 \mathrm{~V} / \mathrm{cm}$, duration $400 \mathrm{~ms}$. There was a lack of $1000 \mathrm{~ms}$ between the pulses. PBS injections with subsequent electroporation $(n=3)$ served as negative controls. Each treated area was marked with 4 dots by tattoo ink stains to locate the treated areas at the end of the study. 


\subsection{B-galactosidase Staining}

Lung biopsies were fixed on ice for 30 to $120 \mathrm{~min}$ in $4 \%$ paraformaldehyde and $0.2 \%$ glutaraldehyde (Sigma-Aldrich, Søborg, Denmark). Next, the biopsies were washed three times in PBS and stained in $1 \mathrm{mg} / \mathrm{mL} \mathrm{X-gal,} 2 \mathrm{mM} \mathrm{MgCl} 2,5 \mathrm{mM} \mathrm{K}_{3} \mathrm{Fe}(\mathrm{CN})_{6}, 5 \mathrm{mM}$ $\mathrm{K}_{4} \mathrm{Fe}(\mathrm{CN})_{6}$, and $0.02 \%$ NP40 dissolved in PBS (Sigma-Aldrich, Søborg, Denmark). This was followed by an in-dark incubation at $37^{\circ} \mathrm{C}$ until a stain appeared. Finally, the biopsies were fixed in $4 \%$ paraformaldehyde, embedded in paraffin, sliced in $4 \mu$ sections, and counterstained with nuclear fast red (Sigma-Aldrich, Søborg, Denmark).

\subsection{Western Blotting}

Cells were lysed in RIPA buffer with protease and phosphatase inhibitors (SigmaAldrich, Søborg, Denmark). The samples were sonicated, subjected to SDS-PAGE, and immunoblotted. The blots were blocked with 2.5\% BSA (Sigma-Aldrich, Søborg, Denmark) or 5\% dry milk (BD) in PBS (Sigma-Aldrich, Søborg, Denmark), containing 0.1\% Tween20 (Sigma-Aldrich, Søborg, Denmark) prior to probing with the following primary antibodies: RFP (AB223), GFP (D5.1), Flag (M2), phosphor-p44/42 MAPK (SC-9101), P-Akt (S473), beta-actin (AC-15), and Vinculin (V9131). Appropriate horseradish peroxidase-conjugated secondary antibodies were used for development (Jackson ImmunoResearch, Ely, UK).

\subsection{Histochemical Analysis}

Tissues were fixed in $4 \%$ formaldehyde or paraformaldehyde overnight, embedded in paraffin and sliced in $4 \mu \mathrm{m}$ sections. Antigen retrieval was performed at $100{ }^{\circ} \mathrm{C}$ in a citrate buffer, pH 6 for 20 min. Sections were blocked in 2.5\% BSA in PBS with $0.1 \%$ Tween 20 and RFP (AB223), or Ki67 (SP6) was used as the primary antibody. Anti-rabbit horseradish peroxidase-conjugated secondary antibody was used for development (Jackson ImmunoResearch). Counterstaining was performed with DAPI (Vector Laboratories, Burlingame, CA, USA).

\subsection{Real-Time Quantitative PCR}

The total RNA from the porcine cells was isolated using the High Pure RNA Isolation Kit (Roche). An amount of 50 ng total RNA was used per sample in combination with the Brilliant III Ultra-Fast SYBR ${ }^{\circledR}$ Green QPCR Master Mix (Agilent Technologies, Glostrup, Denmark) (see Table S1 for primer sequences). Data were analysed with the $\Delta \Delta C T$ method and normalized to GAPDH.

\subsection{8. $P C R$}

PCR was performed on genomic DNA, isolated from chorion villi lysis buffer treated cells or ear biopsies. The Q5 High-Fidelity DNA Polymerase (NEB) was used according to the manufacture's recommendations. See Table S1 for primers.

\subsection{F-Fluorodeoxyglucose Positron Emission Tomography-Computed Tomograph (PET/CT) Scanning}

Whole body 18F-FDG-PET/CT scans were carried out after a $12 \mathrm{~h}$ fast and under isoflurane. $1 \mathrm{~h}$ after IV injection of approximately $300 \mathrm{Mbq}$ 18F-FDG, pigs were scanned on a Siemens Biograph Vision 600 integrated PET/CT system. Data were reconstructed using TrueX + TOF with a $440 \times 440$ matrix, 4 iterations, 5 subsets, a Gaussian filter, and $2 \mathrm{~mm}$ full with half maximum. An experienced nuclear medicine physician, using the Hybrid Viewer software (Hermes Medical Solutions, Stockholm, Sweden), analysed all images.

\subsection{Statistics}

An unpaired 2-tailed Student's t-test was used for statistical analysis of the data. $p$ values $\leq 0.05$ were considered a statistically significant difference between compared groups. The data shown are representative from one out of three or more experiments. 


\section{Results}

\subsection{Design of a Conditional Cas9 Expression Construct}

To generate a transgene minipig with global conditional Cas9 expression, we designed a Sleeping Beauty transposon to deliver the Cas9 gene into the genome of porcine fibroblasts. The conditional Cas9 construct contained a red fluorescent protein (RFP) [29] and 4 polyadenylation signals to terminate transcription flanked by two FRT sites. This design permitted FlpO inducible Cas9 expression. Adding the RFP gene to the construct made it possible to identify cells expressing the transgene. When activated, i.e., the Cas9 expressing cells, they could be visualized by the expression of yellow fluorescent protein (YFP) [30] as the genes were linked by a $2 \mathrm{~A}$ linker peptide [31]. Strong expression of the transgenes was mediated by the CAG promoter [32] (Figure 1A).

A

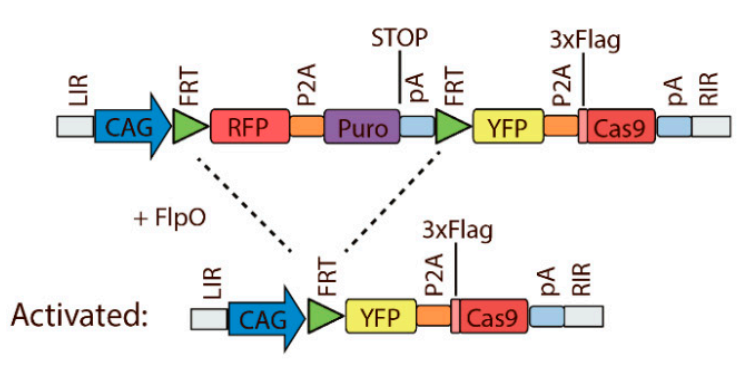

B

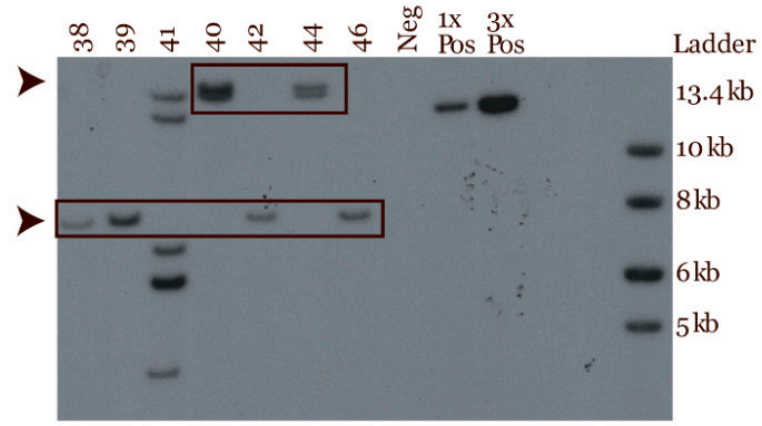

C

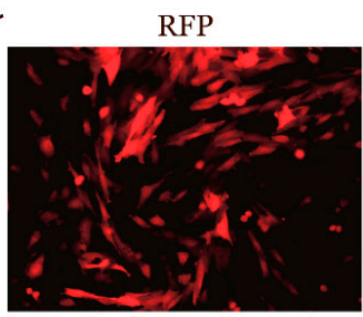

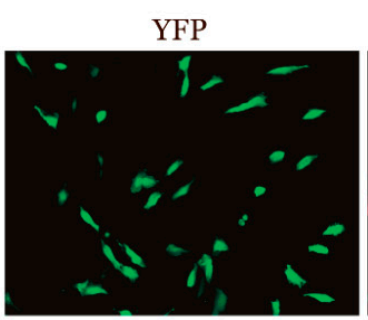

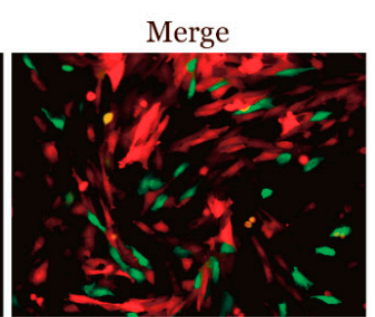

D

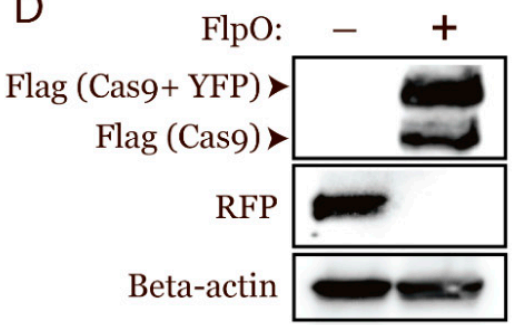

Figure 1. Generation of a transgenic Cas9 minipig. (A) Design of the transgenic FlpO-dependent CRISPR/Cas9 transposon: The CAG promoter drives the expression of the transgene, which initially mediates the expression of the RFP gene and the puromycin selection marker (Puro). The polyadenylation signal (pA) prevents transcription of the downstream YFP and Cas9 genes prior to FlpO-mediated activation. Both gene pairs are separated by 2A linker peptides (P2A). FlpO recombinase mediates construct activation by recombination at the FRT sites. This yields YFP and Cas9 expression. Cas 9 protein contains a Flag tag. (B) Southern blot for the transgene copy number in seven cloned piglets. The arrowheads mark the piglets with one or two copies of the transposon. Pig 41 had six copies of the transposon. (C) Transition from RFP to YFP expressing cells by transfection with the FlpO recombinase. Images were taken after two passages. (D) Western blot on cell extracts seven passages after transfection with the FlpO or empty plasmid. Beta-actin was used as loading control. Western Blot and Southern Blot Images can be found in Figure S7.

\subsection{Generation of a Transgenic Cas9 Minipig by Cloning}

For cloning of the pigs, low passage Cas9 fibroblasts were generated. These fibroblasts were generated by being co-transfected with the aforementioned Cas 9 transposon and the Sleeping Beauty transposase, followed by puromycin selection [28]. Single clones were obtained and screened based on their RFP expression and morphology. The selected clones were pooled and used to generate reconstructed embryos by HMC. In total, 85 blastulae/morulae were obtained. These were transferred to a recipient sow, which farrowed ten piglets, three of which were stillborn, and one died at the age of 5 weeks. The remaining six pigs were healthy and developed as expected.

To arbitrate the copy numbers of the transposon in the cloned pigs, ear biopsies were obtained to isolate primary fibroblasts. DNA from these fibroblasts was used for 
Southern blotting to determine the transposon copy number. Three different clones had been generated, resulting in three piglets with one copy, two piglets with two copies, and one piglet with six copies of the transposon (Figure 1B). The six-copy piglet showed weakness and had to be euthanized 5 weeks after delivery, due to weight loss. The pigs that contained one or two copies of the transposon were successfully used for the production of F1 and F2 generations by crossing with Göttingen minipigs.

The genetic design was validated by transfecting transgenic Cas9 fibroblasts with a FlpO and sgRNA-expressing plasmid or an empty plasmid. Cells transfected with an empty plasmid appeared red, and FlpO transfected cells showed the expected transition from red to yellow cells (appearing green in the applied filter) (Figure 1C). Moreover, a Western blot validated the termination of the RFP expression and the onset of Cas9 expression post transfection (Figure 1D). Overall, minipigs with conditional expression of Cas9 were cloned and viable. Moreover, the introduction of FlpO expression mediated the recombination and expression of Cas9 and YFP protein.

\subsection{Characterization of the Transgenic Expression}

Transgenic expression from a transposon can show varying expression profiles in different tissues and cell types due to the random integration. To analyse the expression from the transposon in vivo, tissue biopsies were collected from major organs from pigs containing one copy of the transposon. The expression for RFP was analysed by qPCR, Western blotting and IVIS scanning. The majority of organs had high levels of expression except from the brain, lymph nodes and spleen (Figure 2A,B and Figure S1). In-depth analysis by immunohistochemistry validated RFP expression, especially in epithelial cells, but also in muscles and hepatocytes (Figure 2C). Collectively, these analyses demonstrated that the transposon is expressed in the majority of organs with a strong expression in epithelial and muscles cells.

\subsection{In Vitro Validation of CRISPR/Cas9-Induced Gene Alterations}

To induce specific mutations, single guide RNAs were designed for the target genes and validated in porcine fibroblasts (Figure S2 and Table S1). A repair template was designed to introduce a KRAS ${ }^{\mathrm{G} 12 \mathrm{D}}$ gain-of-function mutation. The template was validated in fibroblasts by co-transfection with a sgRNA against KRAS and the KRAS ${ }^{\mathrm{G} 12 \mathrm{D}}$ repair template. Single clones were analysed for the introduction of the specific mutation, and clones with the desired KRAS ${ }^{\mathrm{G} 12 \mathrm{D}}$ point mutation were identified (Figure S3). These analyses confirmed the CRISPR/Cas9 induced gene alteration in porcine fibroblasts.

To further validate the genetic design, primary cells isolated from the transgenic Cas 9 piglets were transduced with different viral constructs and appropriate AAV serotypes. All viral constructs contained the FlpO gene and the KRAS ${ }^{\mathrm{G} 12 \mathrm{D}}$ repair template combined with different combinations of sgRNAs (Figure 3A). Three viral constructs were produced: the first containing sgRNAs against STK11, KRAS, and TP53 (SKT), the second containing sgRNAs against PTEN, KRAS, and TP53 (PKT), and the third containing sgRNAs against PTEN, TP53, KRAS, and NOTCH1 (PTKN). Primary fibroblast or keratinocytes were transduced with the three different $\mathrm{AAV}$ particles, and the transition from red to yellow fluorescent was detected, indicating the expression of FlpO from the viral constructs (Figure 3B). Furthermore, fibroblasts transduced with the viral constructs demonstrated a significantly increased proliferation rate compared to non-activated fibroblasts (Figure 3C). Moreover, PKT treated fibroblasts revealed a significant higher proliferation rate than SKT treated fibroblasts. An insertion and deletion (Indel) analysis validated the mutation of the targeted genes and the introduction of the KRAS ${ }^{\mathrm{G} 12 \mathrm{D}}$ point mutation (Figure S4). Western blotting confirmed the transition from RFP to YFP expression, the mutation of the targeted genes by increased phosphorylation of ERK due to the point mutated KRAS ${ }^{\mathrm{G} 12 \mathrm{D}}$, and the phosphorylation of AKT in PKT treated cells as a consequence of the PTEN mutation (Figure 3D). 
A

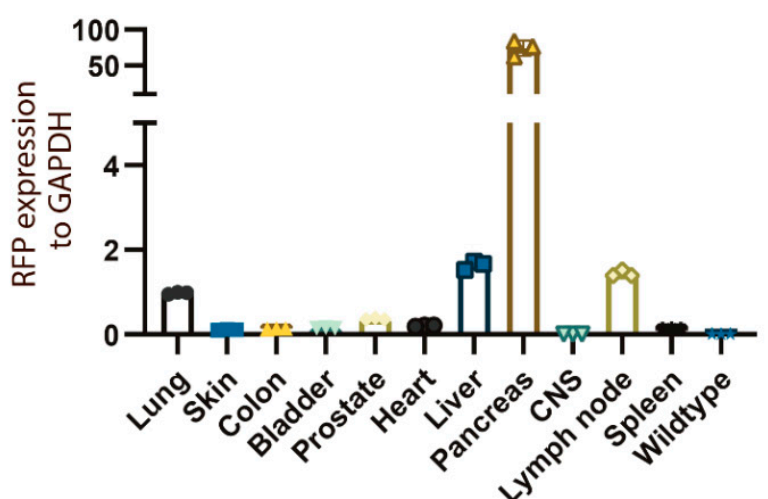

C

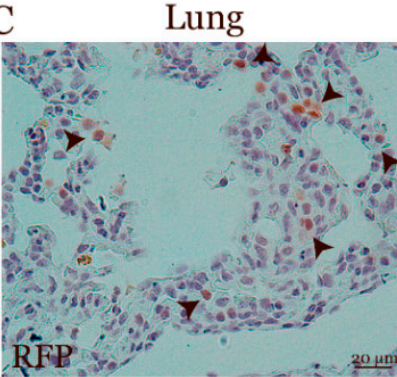

Prostate

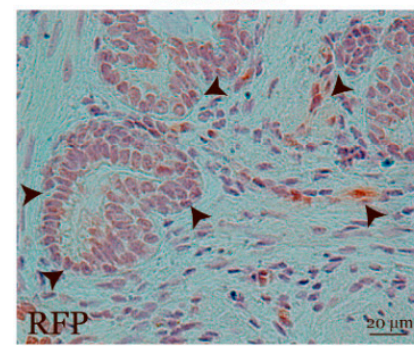

CNS

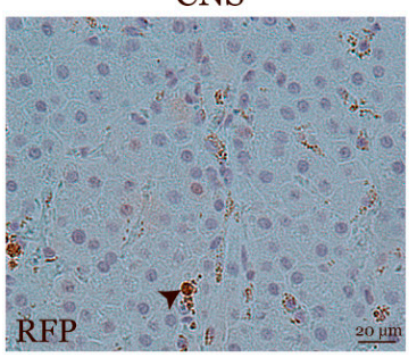

Heart

Lymph node
B
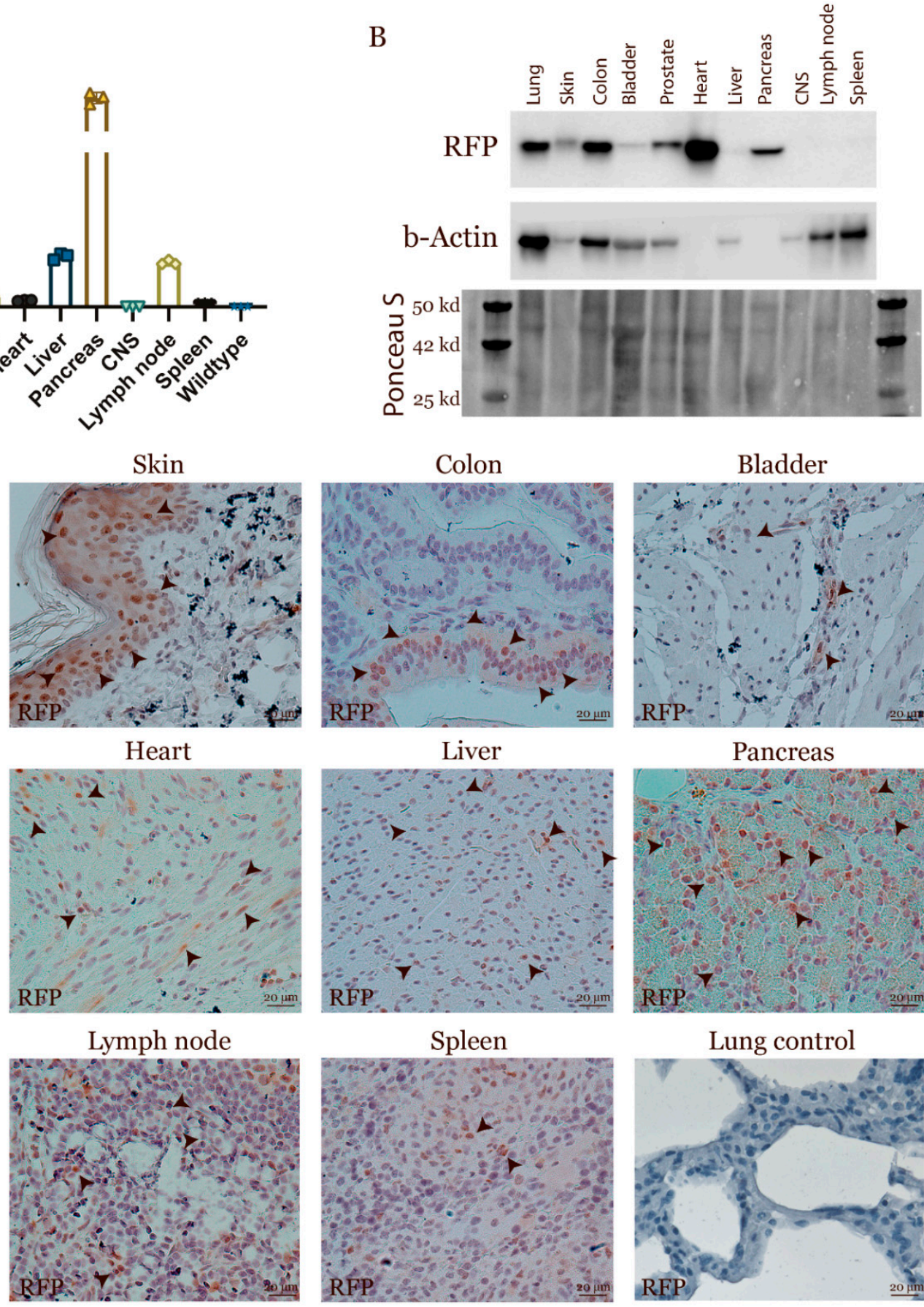

Colon

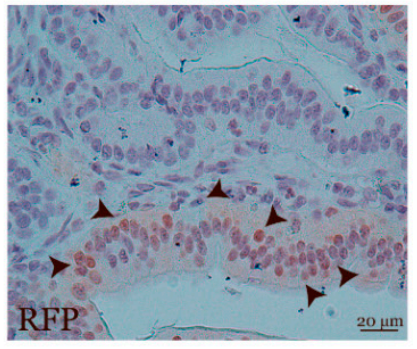

Liver

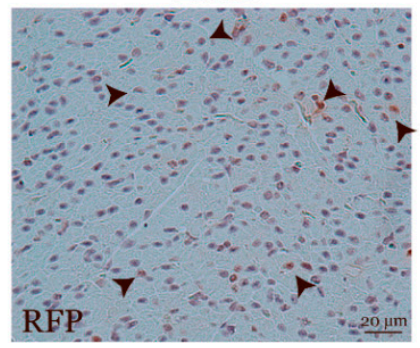

Spleen

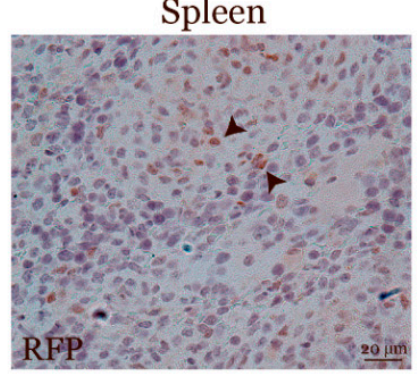

Bladder

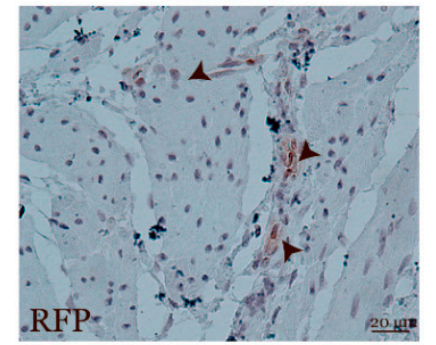

Pancreas

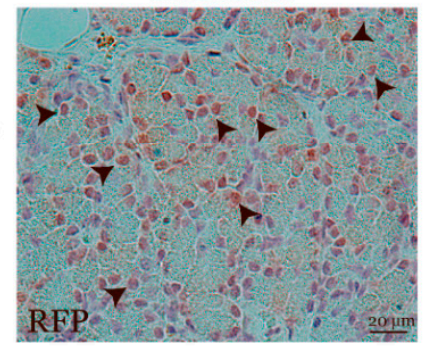

Lung control

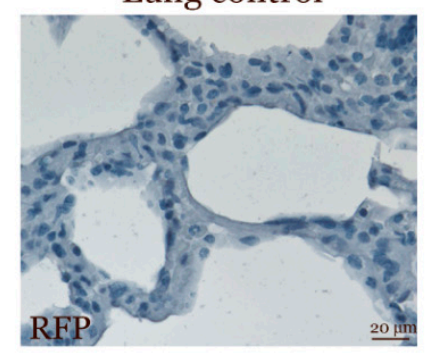

Figure 2. Expression profile of RFP in multiple organs. (A) Expression of RFP in multiple organs was assessed by qPCR. Expression was normalized to GAPDH, and the expression in lung tissues was set to $1(n=3)$. (B) Western blot RFP was performed on samples from multiple organs. Equal amount of proteins were loaded, and beta-actin and Ponceau $\mathrm{S}$ were used as loading control. (C) Tissue sections for different organs were stained with an antibody against RFP (brown stain). Arrowheads mark the positive cells. Haematoxylin staining was used to stain the nucleus of the cells (blue stain) $(n>3)$. Western Blot Images can be found in Figure S7. 
A SKT viral vector :

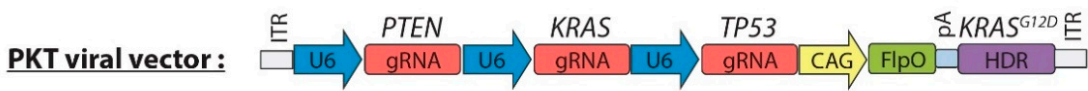

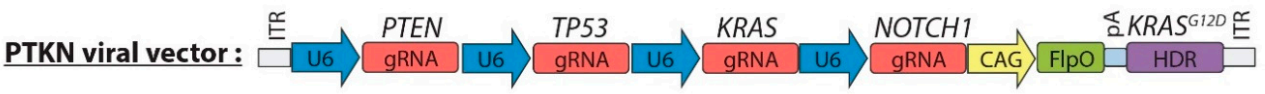

B
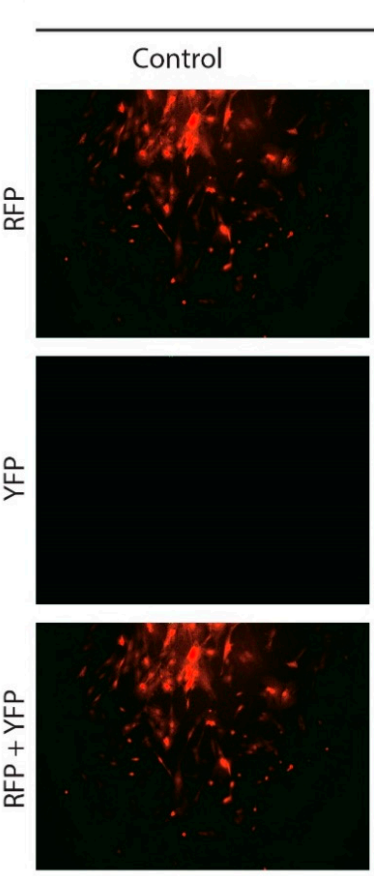

\section{C}

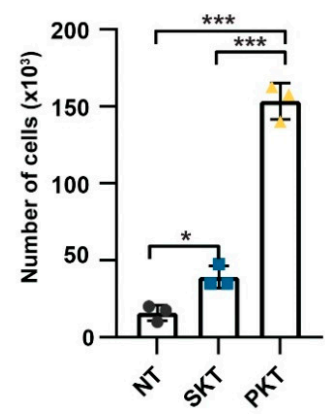

Fibroblast
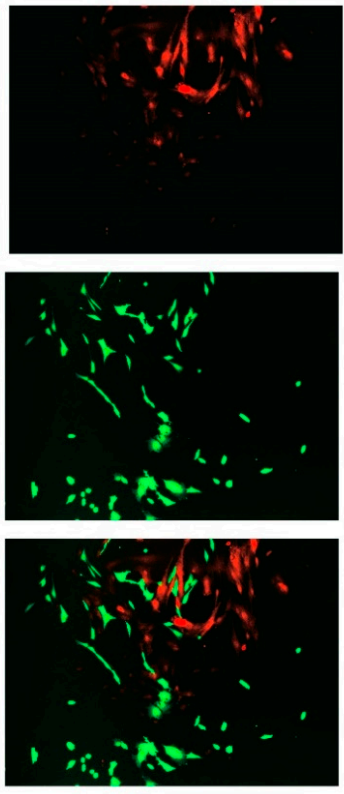

D

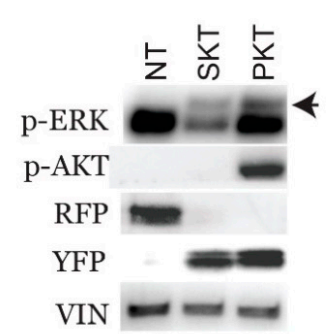

E
Kertenocytes

AAV6
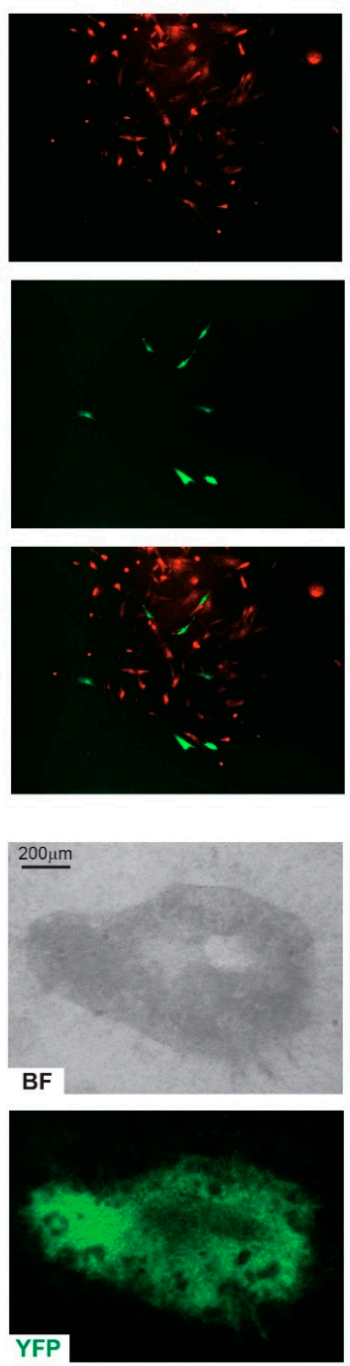
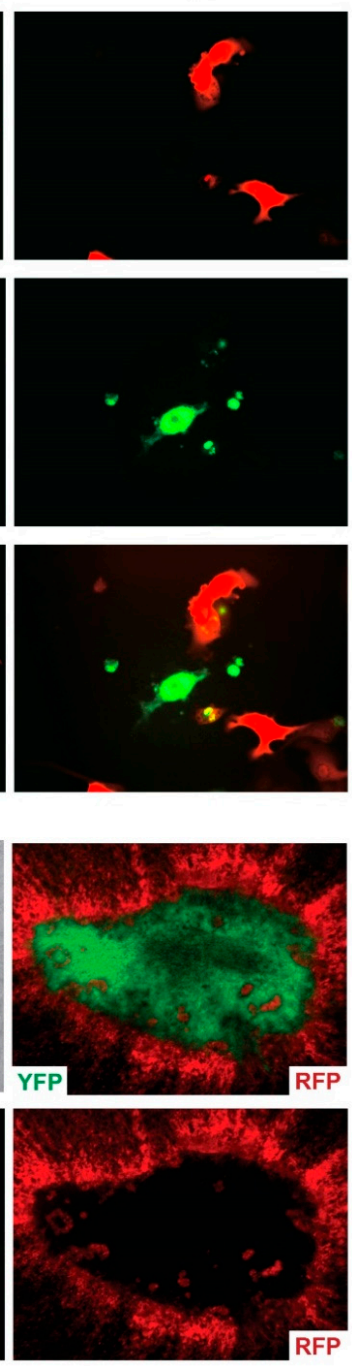

Figure 3. CRISPR-induced mutation in vitro. (A) Overview of the AAV viral vectors containing the FlpO gene used to activate the Cas9 expression, a KRASG12D repair template and sgRNAs against the following target genes: STK11, KRAS, TP53 (SKT). PTEN, TP53, KRAS (PKT). PTEN, TP53, KRAS, and NOTCH1 (PTKN). (B) Primary fibroblasts and keratinocytes were transduced with AAV particles, containing sgRNAs and FlpO expression. Transformed cells turn from red to yellow upon FlpO recombination. Images were taken after one passage of the cells. (C) Proliferation assay on non-treated, SKT_AAV2H22 or PKT_AAV9-treated Cas9 fibroblasts. Cells had undergone five passages before the proliferation was measured. ${ }^{*} p<0.05,{ }^{* * *} p<0.001$. (D) Western blot on protein lysate from the proliferation assay. Black arrow marks p-ERK. Vinculin (VIN) was used as loading control. (E) Image 6 weeks after SKT_AAV2H22-treated air-liquid interface (ALI) Cas9 pig pseudostratified, ciliated, columnar tracheobronchial epithelial cells. Western Blot Images can be found in Figure S7. 
Two of the viral constructs, STK and PKT, were generated to induce lung cancer in the Cas9 transgene pigs. To validate the viral construct in lung epithelial cells, an ex vivo lung culture assay was established of basal tracheobronchial epithelial cells. Transduction of the lung epithelial cells revealed an expansion of transduced cells surrounded by non-treated cells. This shows that the transformed cells could overcome contact inhibition from their surroundings (Figure 3E). In summary, transduced cells demonstrated a proliferation gain and that they overcame contact inhibition. These data reveal the validity of the genetic design in vitro and its potential for the induction of cancer by an increased proliferation and an overcoming of contact inhibition.

\subsection{In Vivo Activation of Cas9 Expression by FlpO-Mediated Recombination}

The skin of the pig shows high similarity to humans and can, thus, serve as a comparable model. To demonstrate in vivo recombination and activation of Cas9 expression, the skin of Cas9 minipigs was investigated. The delivery of sgRNAs and FlpO was achieved by intradermal injections of PTKN_AAV6 particles or PTKN plasmid, followed by electroporation or only PTKN_AAV6 transduction (Figure 4A). Skin biopsies were taken 1 month post treatment and a histology analysis was performed. The histology and proliferation were similar between normal skin and samples that received sgRNAs a and FlpO-expressing construct (Figure 4A). To assess the samples for the presence of the viral construct, a PCR analysis was performed. All biopsies from the AAV-transduced skin were positive for the presence of the viral vector. Two biopsies from the electroporated areas were positive, and the combined delivery of AAV and electroporation had one positive sample (Figure 4B). CRISPR/Cas9-induced mutations were analysed by Sanger sequencing, but no mutations were detected by this method. To confirm the recombination at the FlpO site and hereby the activation of Cas9 expression, a transition PCR analysis was performed (Figure 4B). An FlpO mediated excision of the stop cassette was confirmed in two biopsies, and Sanger sequencing validated the recombination (Figure $4 \mathrm{C}$ ). To ensure that Cas9 protein was expressed, the biopsies were analysed by Western blotting which revealed an expression of the Cas9 protein (Figure 4D). Overall, these analyses confirm that Cas9 protein can be expressed in vivo by the delivery of FlpO. 
A
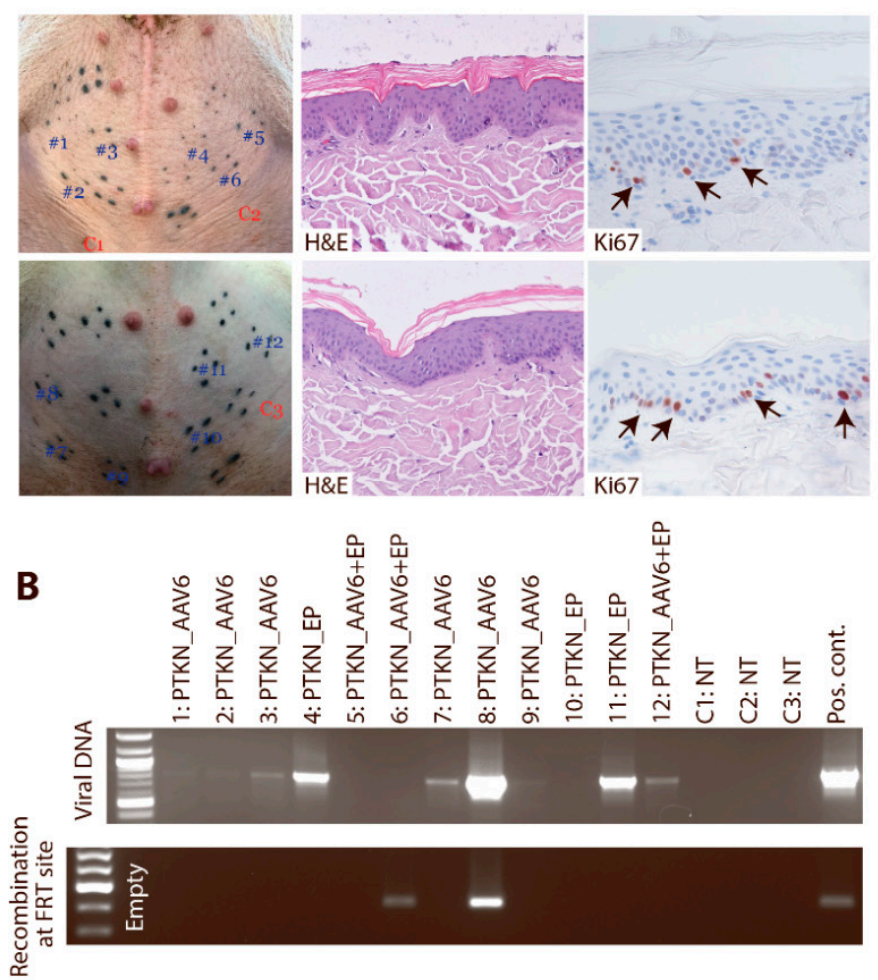

C
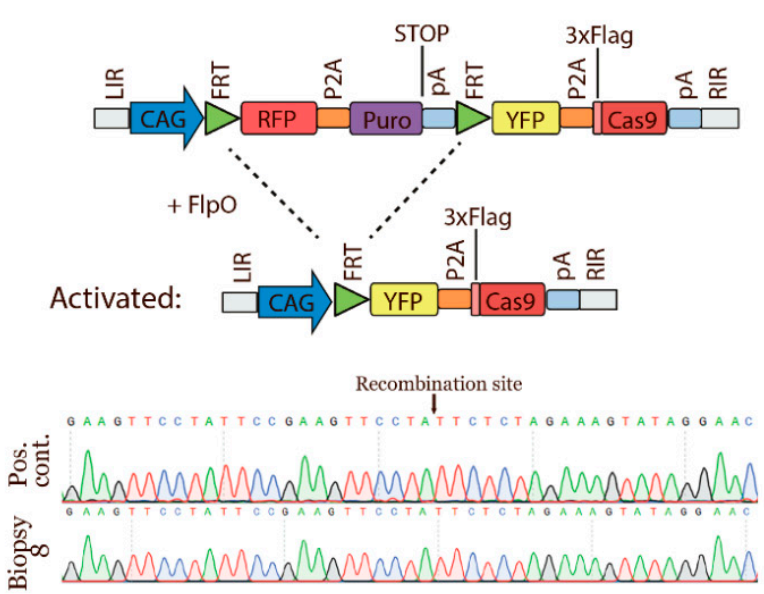

D

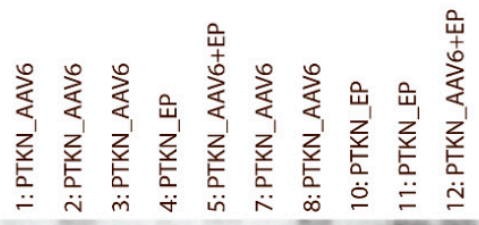

Flag (Cas9)

Beta-actin

Figure 4. In vivo activation of Cas9 expression. Cas9 minipigs were transduced in multiple areas in the abdominal skin, and biopsies were taken after 1 month. (A) Tissue sections from transduced areas and control skin were stained for H\&E and Ki67 $(n>3)$. (B) Biopsies were analysed for the presence of viral DNA and for recombination at the FRT sites and hereby activation of Cas9 expression. The PTKN construct was used as either plasmid or in AAV6 particles. Some areas underwent electroporation (EP) to enhance the delivery. NT: nontreated. (C) Two samples underwent Sanger sequencing to confirm recombination of the transposon at the FRT sites. (D) Proteins isolated from the biopsies were analysed by Western blotting for Cas9-Flag expression. Beta-actin was used as loading control. Western Blot Images can be found in Figure S7.

\subsection{Induction of Lung Cancer}

To assess an in vivo gene alteration by CRISPR/Cas9 and ultimo the induction of cancer, lung tissue was transduced by AAV particles. Prior to the induction of lung cancer, the delivery of viral particles to the lung epithelium had to be addressed. Pilot studies demonstrated that reporter viruses with serotype AAV2H22 or AAV9 transduced pig lung epithelium by assessing $\beta$-galactosidase staining and immunohistochemical staining for GFP, respectively (Figure S5). Hereafter, 13 Cas9 minipigs were infected with $10^{12} \mathrm{vg}$ of SKT_AAV2H22 alone or SKT_AAV2H22 [33,34] and PKT_AAV9 in combination. The viral particles were delivered as aerosols or with a bronchoscope to the lungs. The pigs were monitored for cancer development by FDG-PET/CT-scans up to three times over a period of 18 months (Figure 5A). Three of the pigs showed minor abnormalities in the lungs by FDG-PET/CT scanning. One had an opacity in a part of a lobe. At termination, biopsies were analysed by histology and revealed features of inflammation (Figure 5B), which is fully compatible with the scans. One pig had a dense spot with a diameter of $5 \mathrm{~mm}$ at 8 months post transduction. After 13 months, an increased FDG-uptake was observed in this spot compared to the background-an indication of increased metabolism (Figure 5C). At termination, the foci were identified and revealed a calcification deposit. Multiple samples from different pigs were analysed for CRISPR-induced mutations by Sanger sequencing, but this method could not detect any alterations induced by the sgRNAs. In summary, these analyses revealed that targeting up to three genes simultaneously by AAV 
delivery of sgRNA to the lung tissue was not sufficient to induce cancer over a period of 18 months.
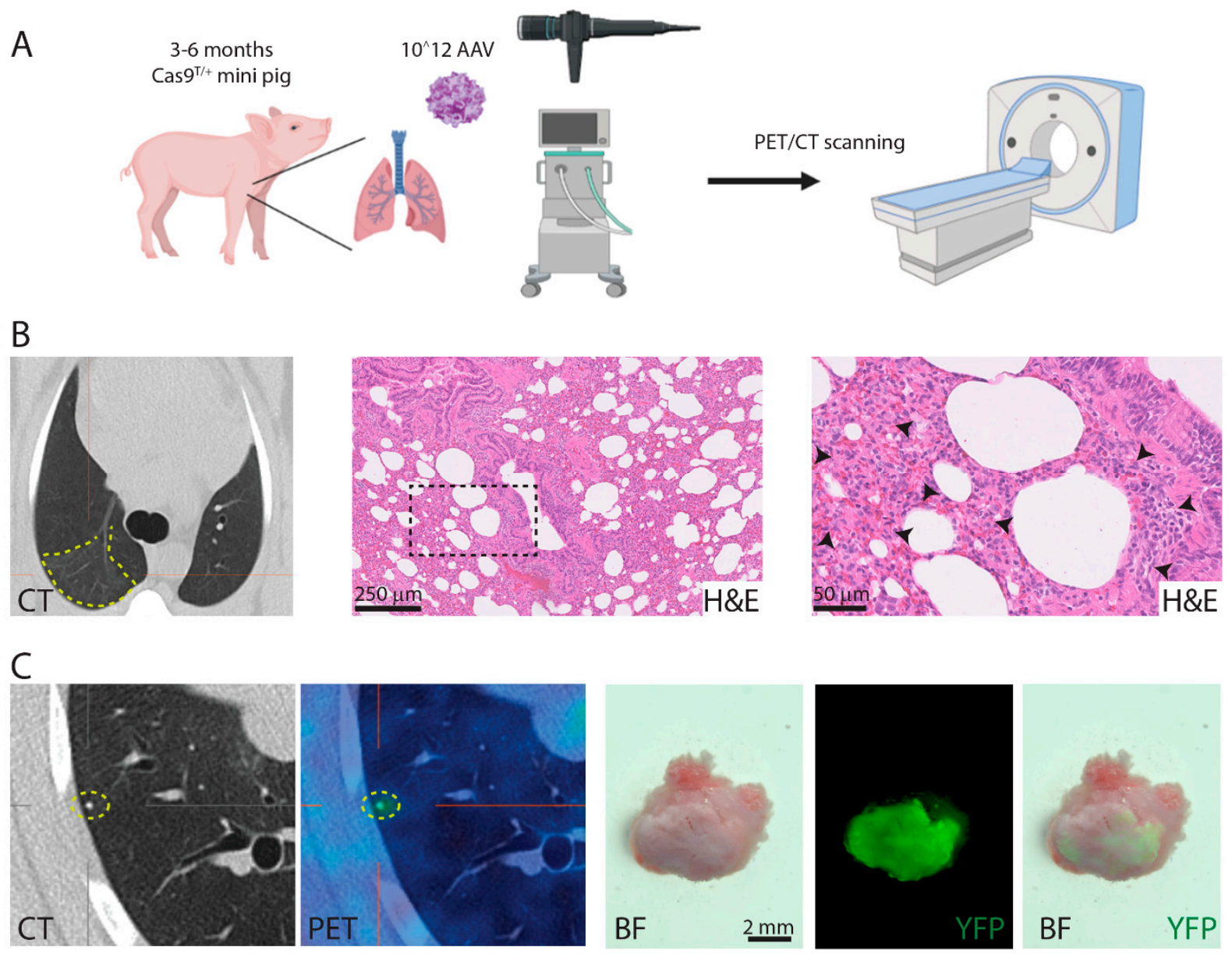

Figure 5. Delivery of AAV particles to the lungs. (A) Transgenic Cas9 pigs were transduced with $10^{12}$ AAV particles by aerosol or through a bronchoscope. The pigs were PET/CT scanned up to three times over 18 months after AAV transduction. (B) Inflammation in a lung lobe after AAV induction. Histology analysis revealed chronic inflammation by infiltrating lymphocytes (marked by black arrowheads). (C) PET/CT scanning shows increase FDG uptake in area of $5 \mathrm{~mm}^{3}$. Analysis of the spot revealed calcification with auto-fluorescent seen as YFP.

\section{Discussion}

Only a few models of cancer have been generated in large animals, as most models are based on rodents. The establishment of large animal models is an unmet need, as they have, in many aspects, a much higher similarity to humans [4-6]. Though, humans, as well as pigs, are less predisposed to develop cancer than mice [35]. In this study, we cloned a minipig with a Cas9-expressing construct controlled by FlpO recombinase. By an introduction of Cas9 to the porcine genome, it is possible to genetically alter genes by delivering sgRNAs. We have shown that different primary cells derived from the Cas 9 minipig can be modified by CRISPR in vitro. Furthermore, the in vivo activation of Cas 9 by a recombination through the expression of FlpO was performed in the skin. Hereby, we have applied the CRISPR/Cas system to the porcine cells, allowing for genetic alteration by specific sgRNAs.

In line with our Cas9 minipig, Wang et al. generated a CRISPR/Cas9 pig. Here, Wang et al. showed both, in vitro and in vivo gene alteration introduced by sgRNAs, which resulted in lung cancer formation [36]. They infected two 1 week old transgenic pigs with $5 \times 10^{6}$ lentiviral particles and observed lung cancer 3 months post treatment. This shows that it is possible to generate lung cancer in pigs by the CRISPR/Cas9 tech- 
nology. In contrast to our study, they relied on the Cre-LoxP system to induce the Cas9 expression $[37,38]$. They used a lentivirus as a vector, and they introduced mutations to BRCA1 BRCA2, APC, PTEN, TP53, and KRAS. We delivered $10^{12}$ AAV particles but did not observe lung cancer after 18 months. The lentivirus is integrated into the genome, unlike the AAV, which could accelerate cancer formation. Cancer induction in their pig model resembles tumour formation in a similar Cas9 mouse model, where we and others have shown cancer formation 3 months post transduction with AVV particles containing sgRNAs $[19,20]$. Multiple discrepancies between their and our model could explain the different outcomes. One may be related to the strain background of the used pigs or the time of delivery of sgRNAs. This could explain a later unset of lung cancer but is less likely to explain the lack of cancer formation, as the pigs were followed for 18 months. An analysis of the transgene expression from our transgenic pig varied among organs and even within tissues. A comparison of the tissues was compromised by a lack of uniform house-keeping genes. Immunohistochemistry for transgene expression revealed mosaic expression. In the lung, we estimated the expression of the transgene to be present in $25 \%$ of the epithelial cells. Therefore, we used additional amounts of AAV particles, to ensure the transduction of the Cas9-expressing cells. Future work will share light on this discrepancy and improve the robustness of cancer models in pigs.

The frequency of cancer in larger animals is similar or lower when compared to small animals, suggesting that large animals have evolved additional tumour suppressor functions $[3,35]$. We have compared mouse with porcine models by targeting the same genes in the pig that introduced lung cancer in mice by the use of the CRISPR/Cas9 technology $[19,20]$. The lack of cancer formation in the pig suggests a significant discrepancy between both models. At this stage, it remains unclear if this is related to biological differences or to external factors. One potential difference is the infection status in housing facilities for mice and pigs, which may affect the immune response towards the AAV, Cas9, or tumour surveillance. FDG-PET/CT-imaging revealed minor abnormalities in the lungs of pigs treated with the viral constructs by AAV transduction. A post-mortem examination of the pigs 18 months after the treatment identified these abnormalities as calcified deposits with no indication of mutations in target genes. In both, humans and pigs, foci with calcified deposits are observed as remains of immune responses against pathogens or sarcoidosis. These deposits originate from granulomas that harden over time [39,40]. The calcified foci we observed in our pigs could originate from our AAV treatment, since we also observed chronic inflammation in some pigs. This would explain why we did not observe the expected cancer formation, as the increased immune surveillance could have cleared transformed cells. FDG-PET/CT scanning of the pigs revealed activated lymph nodes, especially in the lungs and the colon (Figure S6), indicating an activated immune system, as it has been observed in other porcine models of cancer [41]. Together, these data indicate that a strong immune response can be induced in pigs, which could lead to cancer immune surveillance.

\section{Conclusions}

In conclusion, we developed a porcine model with inducible Cas9 expression in the majority of organs. We validated the model in vitro in fibroblasts, keratinocytes, and pseudo-stratified lung epithelial cultures and in vivo in the skin of the minipigs by Cas9 construct activation through AAV transduction. Thus, an in vitro and, potentially, an in vivo model of human cancer has been generated in a minipig for pre-clinical studies.

Supplementary Materials: The following are available online at https: / www.mdpi.com/article / 10.3390/cancers13123024/s1, Figure S1: Transgenic expression, Figure S2: Validation of sgRNA in porcine fibroblast, Figure S3: Introduction of KRASG12D point mutation by HDR, Figure S4: ICE analysis for AAV induces mutations in vitro, Figure S5: AAV targeting of pig lung epithelium, Figure S6: Activated lymph nodes, Figure S7. Uncropped Western Blot and Southern Blot images, Table S1: Primers. 
Author Contributions: Conceptualization, M.F.B., J.E.J. and M.K.T.; methodology, M.F.B., J.E.J., A.K.O.A., S.H.S., F.D.-H., U.B.J., Y.L. (Ying Liu), H.C. (Henrik Callesen), M.H.V. and M.K.T.; validation, M.F.B., M.H.V. and M.K.T.; investigation, M.F.B., J.E.J., M.R., H.C. (Huiqiang Cai), A.K.O.A., S.H.S., F.D.-H., Y.L. (Yonglun Luo), U.B.J., H.C. (Huiqiang Cai), H.H., M.H.V. and M.K.T.; writing-original draft preparation, M.F.B. and M.K.T.; supervision, M.K.T. and M.H.V.; funding acquisition, M.K.T. All authors have read and agreed to the published version of the manuscript.

Funding: This research was funded by AUFF NOVA (AUFF-E-2015-FLS-9-8), the Danish Cancer Society (R146-A9394), Ellegaard Göttingen Minipigs Research Foundation grants, Aage og Johanne Louis-Hansen's fund, Fabricant Einar Willumsens memorial fund, Director Emil C. Hertz and wife Inger Hertz's fund, Helge Peetz and Verner and wife Vilma Peetz fund, Karen Elise Jensen's fund and from The Aarhus University Research Foundation, Denmark. MFB was co-funded by The Graduate School of Health, Aarhus University.

Institutional Review Board Statement: The study was conducted according to the guidelines of the Declaration of Helsinki and animal experiments were conducted and approved by the Danish Animal Experiments Inspectorate (license no. 2017-15-0201-01243, date of approval the 28 June 2017). Housing and care of the transgenic pigs were in accordance with the Danish animal research proposal on genetically modified animals.

Informed Consent Statement: Not applicable.

Data Availability Statement: Data is contained within the article or supplementary material.

Acknowledgments: We would like to thank Hanne Skovsgaard Pedersen, Janne Adamsen, Ruth Kristensen, Anette M. Pedersen and Klaus Villemoes for the expert technical assistance regarding blastula/morula production. We would also like to thank Anette Thomsen for aid in the isolation of keratinocytes, Jacob T. Jensen for teaching MFB how to establish an ALI culture and Simone S. Møller for helping with fibroblast cultures. André Walter for proofreading the manuscript. Finally, our gratitude goes to Dirk Grimm's laboratory, especially Anne-Katrine Hamann, for teaching MFB to produce and purify AAV. AAV2H22 plasmid was a kindly gift from Joseph Zabner and David Schaffer.

Conflicts of Interest: The authors declare no conflict of interest.

\section{References}

1. Kellar, A.; Egan, C.; Morris, D. Preclinical Murine Models for Lung Cancer: Clinical Trial Applications. BioMed Res. Int. 2015, 2015, 1-17. [CrossRef] [PubMed]

2. Mak, I.W.Y.; Evaniew, N.; Ghert, M. Lost in translation: Animal models and clinical trials in cancer treatment. Am. J. Transl. Res. 2014, 6, 114-118. [PubMed]

3. Tollis, M.; Boddy, A.M.; Maley, C.C. Peto's Paradox: How has evolution solved the problem of cancer prevention? BMC Biol. 2017, 15, 60. [CrossRef] [PubMed]

4. Watson, A.L.; Carlson, D.F.; Largaespada, D.A.; Hackett, P.B.; Fahrenkrug, S.C. Engineered Swine Models of Cancer. Front. Genet. 2016, 7, 194-198. [CrossRef]

5. Wolf, E.; Kind, A.; Aigner, B.; Schnieke, A. Genetically Engineered Large Animals in Biomedicine. In Animal Biotechnology 2; Springer International Publishing: Cham, Switzerland, 2018; pp. 169-214.

6. Gupta, R.C. Biomarkers in Toxicology, 2nd ed.; Elsevier/Academic Press: Waltham, MA, USA, 2019; p. xxiv. 1222p.

7. Kalla, D.; Kind, A.; Schnieke, A. Genetically Engineered Pigs to Study Cancer. Int. J. Mol. Sci. 2020, 21, 488. [CrossRef]

8. Flisikowska, T.; Kind, A.; Schnieke, A. Pigs as models of human cancers. Theriogenology 2016, 86, 433-437. [CrossRef]

9. Robertson, N.; Schook, L.B.; Schachtschneider, K.M. Porcine cancer models: Potential tools to enhance cancer drug trials. Expert Opin. Drug Discov. 2020, 15, 893-902. [CrossRef]

10. Schachtschneider, K.M.; Liu, Y.; Mäkeläinen, S.; Madsen, O.; Rund, L.A.; Groenen, M.A.M.; Schook, L.B. Oncopig soft-tissue sarcomas recapitulate key transcriptional features of human sarcomas. Sci. Rep. 2017, 7, 2624. [CrossRef]

11. Leuchs, S.; Saalfrank, A.; Merkl, C.; Flisikowska, T.; Edlinger, M.; Durkovic, M.; Rezaei, N.; Kurome, M.; Zakhartchenko, V.; Kessler, B.; et al. Inactivation and Inducible Oncogenic Mutation of p53 in Gene Targeted Pigs. PLoS ONE 2012, 7, e43323. [CrossRef]

12. Sieren, J.C.; Meyerholz, D.K.; Wang, X.J.; Davis, B.T.; Newell, J.D.; Hammond, E.; Rohret, J.A.; Rohret, F.A.; Struzynski, J.T.; Goeken, J.A.; et al. Development and translational imaging of a TP53 porcine tumorigenesis model. J. Clin. Investig. 2014, 124, 4052-4066. [CrossRef] [PubMed]

13. Callesen, M.M.; Árnadóttir, S.S.; Lyskjær, I.; Ørntoft, M.B.W.; Høyer, S.; Dagnæs-Hansen, F.; Liu, Y.; Li, R.; Callesen, H.; Rasmussen, M.H.; et al. A genetically inducible porcine model of intestinal cancer. Mol. Oncol. 2017, 11, 1616-1629. [CrossRef] 
14. Berthelsen, M.F.; Callesen, M.M.; Østergaard, T.S.; Liu, Y.; Li, R.; Callesen, H.; Dagnæs-Hansen, F.; Hamilton-Dutoit, S.; Jakobsen, J.E.; Thomsen, M.K. Pancreas specific expression of oncogenes in a porcine model. Transgenic Res. 2017, 26, 603-612. [CrossRef]

15. Niu, G.; Hellmuth, I.; Flisikowska, T.; Pausch, H.; Rieblinger, B.; Carrapeiro, A.; Schade, B.; Bohm, B.; Kappe, E.; Fischer, K.; et al. Porcine model elucidates function of p53 isoform in carcinogenesis and reveals novel circTP53 RNA. Oncogene 2021, 40, 1896-1908. [CrossRef]

16. Hsu, P.D.; Lander, E.S.; Zhang, F. Development and applications of CRISPR-Cas9 for genome engineering. Cell 2014, 157, 1262-1278. [CrossRef]

17. Riedel, M.; Berthelsen, M.F.; Cai, H.; Haldrup, J.; Borre, M.; Paludan, S.R.; Hager, H.; Vendelbo, M.H.; Wagner, E.F.; Bakiri, L.; et al. In vivo CRISPR inactivation of Fos promotes prostate cancer progression by altering the associated AP-1 subunit Jun. Oncogene 2021. [CrossRef]

18. Riedel, M.; Berthelsen, M.F.; Bakiri, L.; Wagner, E.F.; Thomsen, M.K. Virus Delivery of CRISPR Guides to the Murine Prostate for Gene Alteration. J. Vis. Exp. 2018, 2018, e57525. [CrossRef]

19. Berthelsen, M.F.; Leknes, S.L.; Riedel, M.; Pedersen, M.A.; Joseph, J.V.; Hager, H.; Vendelbo, M.H.; Thomsen, M.K. Comparative Analysis of Stk11/Lkb1 versus Pten Deficiency in Lung Adenocarcinoma Induced by CRISPR/Cas9. Cancers 2021, $13,974$. [CrossRef]

20. Platt, R.J.; Chen, S.; Zhou, Y.; Yim, M.J.; Swiech, L.; Kempton, H.R.; Dahlman, J.E.; Parnas, O.; Eisenhaure, T.M.; Jovanovic, M.; et al. CRISPR-Cas9 Knockin Mice for Genome Editing and Cancer Modeling. Cell 2014, 159, 440-455. [CrossRef]

21. Hammer, R.E.; Pursel, V.G.; Rexroad, C.E.; Wall, R.J.; Bolt, D.J.; Ebert, K.M.; Palmiter, R.D.; Brinster, R.L. Production of transgenic rabbits, sheep and pigs by microinjection. Nature 1985, 315, 680-683. [CrossRef]

22. Vajta, G.; Kragh, P.M.; Mtango, N.R.; Callesen, H. Hand-made cloning approach: Potentials and limitations. Reprod. Fertil. Dev. 2005, 17, 97-112. [CrossRef]

23. Wilmut, I.; Schnieke, A.E.; McWhir, J.; Kind, A.J.; Campbell, K.H. Viable offspring derived from fetal and adult mammalian cells. Nature 1997, 385, 810-813. [CrossRef]

24. Bollen, P.; Ellegaard, L. The Göttingen minipig in pharmacology and toxicology. Pharmacol. Toxicol. 1997, 80 (Suppl. 2), 3-4. [CrossRef]

25. Kragh, P.M.; Nielsen, A.L.; Li, J.; Du, Y.; Lin, L.; Schmidt, M.; Bøgh, I.B.; Holm, I.E.; Jakobsen, J.E.; Johansen, M.G.; et al. Hemizygous minipigs produced by random gene insertion and handmade cloning express the Alzheimer's disease-causing dominant mutation APPsw. Transgenic Res. 2009, 18, 545-558. [CrossRef]

26. Schmidt, M.; Kragh, P.M.; Li, J.; Du, Y.; Lin, L.; Liu, Y.; Bøgh, I.B.; Winther, K.D.; Vajta, G.; Callesen, H. Pregnancies and piglets from large white sow recipients after two transfer methods of cloned and transgenic embryos of different pig breeds. Theriogenology 2010, 74, 1233-1240. [CrossRef] [PubMed]

27. Raymond, C.S.; Soriano, P. High-efficiency FLP and PhiC31 site-specific recombination in mammalian cells. PLoS ONE 2007, 2, e162. [CrossRef]

28. Jakobsen, J.E.; Li, J.; Kragh, P.M.; Moldt, B.; Lin, L.; Liu, Y.; Schmidt, M.; Winther, K.D.; Schyth, B.D.; Holm, I.E.; et al. Pig transgenesis by Sleeping Beauty DNA transposition. Transgenic Res. 2011, 20, 533-545. [CrossRef]

29. Shcherbo, D.; Murphy, C.S.; Ermakova, G.V.; Solovieva, E.A.; Chepurnykh, T.V.; Shcheglov, A.S.; Verkhusha, V.V.; Pletnev, V.Z.; Hazelwood, K.L.; Roche, P.M.; et al. Far-red fluorescent tags for protein imaging in living tissues. Biochem. J. 2009, 418, 567-574. [CrossRef]

30. Nagai, T.; Ibata, K.; Park, E.S.; Kubota, M.; Mikoshiba, K.; Miyawaki, A. A variant of yellow fluorescent protein with fast and efficient maturation for cell-biological applications. Nat. Biotechnol. 2002, 20, 87-90. [CrossRef]

31. Szymczak-Workman, A.L.; Vignali, K.M.; Vignali, D.A.A. Design and Construction of 2A Peptide-Linked Multicistronic Vectors. Cold Spring Harb. Protoc. 2012, 2012, 199-204. [CrossRef]

32. Alexopoulou, A.N.; Couchman, J.R.; Whiteford, J.R. The CMV early enhancer/chicken beta actin (CAG) promoter can be used to drive transgene expression during the differentiation of murine embryonic stem cells into vascular progenitors. BMC Cell Biol. 2008, 9, 2. [CrossRef] [PubMed]

33. Steines, B.; Dickey, D.D.; Bergen, J.; Excoffon, K.J.; Weinstein, J.R.; Li, X.; Yan, Z.; Abou Alaiwa, M.H.; Shah, V.S.; Bouzek, D.C.; et al. CFTR gene transfer with AAV improves early cystic fibrosis pig phenotypes. JCI Insight 2016, 1, e88728. [CrossRef]

34. Koerber, J.T.; Klimczak, R.; Jang, J.H.; Dalkara, D.; Flannery, J.G.; Schaffer, D.V. Molecular evolution of adeno-associated virus for enhanced glial gene delivery. Mol. Ther. 2009, 17, 2088-2095. [CrossRef] [PubMed]

35. Lunney, J.K. Advances in swine biomedical model genomics. Int. J. Biol. Sci. 2007, 3, 179-184. [CrossRef]

36. Wang, K.; Jin, Q.; Ruan, D.; Yang, Y.; Liu, Q.; Wu, H.; Zhou, Z.; Ouyang, Z.; Liu, Z.; Zhao, Y.; et al. Cre-dependent Cas9-expressing pigs enable efficient in vivo genome editing. Genome Res. 2017, 27, 2061-2071. [CrossRef]

37. Silver, D.P.; Livingston, D.M. Self-excising retroviral vectors encoding the cre recombinase overcome Cre-mediated cellular toxicity. Mol. Cell 2001, 8, 233-243. [CrossRef]

38. Takata, Y.; Kondo, S.; Goda, N.; Kanegae, Y.; Saito, I. Comparison of efficiency between FLPe and Cre for recombinase-mediated cassette exchange in vitro and in adenovirus vector production. Genes Cells 2011, 16, 765-777. [CrossRef]

39. Khan, A.N.; Al-Jahdali, H.H.; Allen, C.M.; Irion, K.L.; Al Ghanem, S.; Koteyar, S.S. The calcified lung nodule: What does it mean? Ann. Thorac. Med. 2010, 5, 67-79. [CrossRef] 
40. McGavin, M.D.; Carlton, W.; Zachary, J.F.; Thomson, R.G. Thomson's Special Veterinary Pathology, 3rd ed.; Mosby: St. Louis, MO, USA, 2001; p. xi. 755p.

41. Overgaard, N.H.; Principe, D.R.; Schachtschneider, K.M.; Jakobsen, J.T.; Rund, L.A.; Grippo, P.J.; Schook, L.B.; Jungersen, G. Genetically induced tumors in the oncopig model invoke an antitumor immune response dominated by cytotoxic CD8 $\beta^{+} \mathrm{T}$ cells and differentiated $\gamma \delta \mathrm{T}$ cells alongside a regulatory response mediated by foxp $3^{+} \mathrm{t}$ cells and immunoregulatory molecules. Front. Immunol. 2018, 9, 1301. [CrossRef] 